\title{
Development of a Barthel Index based on dyspnea for patients with respiratory diseases
}

\author{
This article was published in the following Dove Press journal: \\ International Journal of COPD \\ 7 June 2016 \\ Number of times this article has been viewed
}

\author{
Michele Vitacca' \\ Mara Paneroni' \\ Paola Baiardi² \\ Vito De Carolis ${ }^{3}$ \\ Elisabetta Zampogna ${ }^{4}$ \\ Stefano Belli ${ }^{5}$ \\ Mauro Carone ${ }^{3}$ \\ Antonio Spanevello ${ }^{4,6}$ \\ Bruno Balbi ${ }^{5}$ \\ Giorgio Bertolotti ${ }^{7}$ \\ 'Respiratory Rehabilitation Division, \\ Salvatore Maugeri Foundation, IRCCS, \\ Institute of Lumezzane, Brescia, \\ ${ }^{2}$ Scientific Direction, Salvatore \\ Maugeri Foundation, IRCCS, Institute \\ of Pavia, Pavia, ${ }^{3}$ Respiratory Division, \\ Salvatore Maugeri Foundation, \\ IRCCS, Institute of Cassano delle \\ Murge, Bari, ${ }^{4}$ Respiratory Division, \\ Salvatore Maugeri Foundation, \\ IRCCS, Institute of Tradate, Varese, \\ ${ }^{5}$ Respiratory Division, Salvatore \\ Maugeri Foundation, IRCCS, Institute \\ of Veruno, Novara, ${ }^{6}$ Respiratory \\ Diseases Unit, University of Insubria, \\ Varese, ${ }^{7}$ Psychology Unit, Salvatore \\ Maugeri Foundation, IRCCS, Institute \\ of Tradate, Varese, Italy
}

Background: As Barthel Index (BI) quantifies motor impairment but not breathlessness, the use of only this index could underestimate disability in chronic respiratory disease (CRD). To our knowledge, no study evaluates both motor and respiratory disability in CRD during activities of daily living (ADLs) simultaneously and with a unique tool. The objective of this study was to propose for patients with CRD an additional tool for dyspnea assessment during ADLs based on BI items named Barthel Index dyspnea.

Methods: Comprehensibility, reliability, internal consistency, validity, responsiveness, and ability to differentiate between disease groups were assessed on 219 subjects through an observational study performed in an in-hospital rehabilitation setting.

Results: Good comprehensibility, high reliability (interrater intraclass correlation coefficient was 0.93 [ $95 \%$ confidence interval $0.892-0.964$ ] and test-retest intraclass correlation coefficient was 0.99 [95\% confidence interval 0.983-0.994]), good internal consistency (Cronbach's alpha 0.89 ), strong concurrent validity with 6 minute walking distance (Pearson $r=-0.538, P<0.001$ ) and Medical Research Council (Spearman $r_{\mathrm{s}}=0.70, P<0.001$ ), good responsiveness after rehabilitation $(P<0.001)$, and good appropriateness of the index were found evidencing patients with different dyspnea severity. Divergent validity showed weak correlation (Pearson $r=-0.38$ ) comparing Barthel Index dyspnea and BI.

Conclusion: The BI based on dyspnea perception proved to be reliable, sensitive, and adequate as a tool for measuring the level of dyspnea perceived in performing basic daily living activities. A unique instrument simultaneously administered may provide a global assessment of disability during ADLs incorporating both motor and respiratory aspects.

Keywords: activities of daily living, psychometric tests, chronic obstructive pulmonary disease, pulmonary rehabilitation

\section{Introduction}

Dyspnea affects quality of life, exercise tolerance, and mortality in various disease conditions. ${ }^{1}$ Relief from dyspnea during activities of daily living (ADLs) represents the major goal of respiratory rehabilitation ${ }^{2}$ and its quantification through specific instruments (scales) is essential to define disability level and postrehabilitation improvement. ${ }^{3-17}$

Approximately $40 \%$ of patients with chronic obstructive pulmonary disease (COPD) report a degree of disability and 68\% lose at least one relevant function in daily life. ${ }^{18}$

In routine clinical practice, various scales measuring ADLs are used to evaluate patients' motor and functional autonomy/disability, the most widely used being the Barthel Index (BI). ${ }^{19}$ This index was developed for chronic patients and longterm hospital patients with neurological diseases examining their performance
Correspondence: Michele Vitacca Respiratory Rehabilitation Division, Salvatore Maugeri Foundation, IRCCS, Institute of Lumezzane, Via G Mazzini 129, 25065 Lumezzane, Brescia, Italy Tel +39308253182

Fax +39308253189

Email michele.vitacca@fsm.it 
before and after treatment and predicting time needed for motor rehabilitation and amount of nursing aid required. Unfortunately, the BI is not supported as a useful measure of ADLs in respiratory patients. Furthermore, by not taking breathlessness into account, BI equivalents, which quantify motor disability, could underestimate real disability in chronic respiratory disease (CRD).

Up to date there is no study describing the use of an instrument for assessing routinely both motor and respiratory disability. A unique tool could enlighten on these two different outcomes improving prescription of more tailored rehabilitation programs.

The aim of the present study was to describe the development and validation of an additional tool for dyspnea assessment for patients with CRD during ADLs based on the BI items named Barthel Index dyspnea (BI-d). The BI-d is expected to improve the assessment of chronic respiratory patients when administered simultaneously with BI.

\section{Materials and methods}

The study was approved by the Technical and Scientific Committee of the Salvatore Maugeri Foundation (protocol registered: 2013-04; CEC registered: CEC 1078). Patients gave their written informed consent for use of their clinical data for scientific purposes. The present study was carried out in two phases.

\section{Phase I: development of the BI-d}

The development process had two stages.

\section{Stage I}

A team of experts (three lung specialists, five physiotherapists, and one psychologist) discussed the content of the BI-d and the instructions for patients in order to capture their selfevaluation of dyspnea perception during the same ADL items included in the BI. ${ }^{19}$ In detail, experts decided to approach the original BI item on incontinence focusing mainly on dyspnea induced during the act of urinating or defecating instead of the item pertaining incontinence per se, being bladder and bowel control not nearly as central to pulmonary patients. A focus group of ten patients was arranged and patients were asked to answer the questions (performed in Italian) described in the Supplementary materials. The BI-d required someone to interview each patient. In summary, differences between BI and BI-d were related to the patient's evaluation of the dyspnea symptoms during ADLs. In the BI case, operator signed the level of disability according to clinical conditions during ADL; while in the BI-d case, patients gave a judgment to their dyspnea between $0=$ no sign of dyspnea and $4=$ extreme severe level of dyspnea, such as to preclude or reduce specific requested activity. The total BI-d score ranges from 0 (no dyspnea) to 100 (maximum level of dyspnea) according to the original BI grading score. In this pilot phase, patients were also asked to discuss on the comprehensibility of the items describing them as "clear" or "unclear".

\section{Stage 2}

In the second stage, the patient-perceived comprehensibility was tested on a sample of 50 patients. Patients were asked to rank their perceived comprehensibility of the questionnaire on a 4 -point Likert scale, between 0 and $3(0=$ very difficult, $1=$ difficult, $2=$ with low difficulties, and $3=$ no difficulties). Time for completing the BI-d was also assessed. Reliability of BI-d was assessed by means of interrater reliability (two raters) and of test-retest reliability between admission and 48 hours from admission maintaining the same interviewer. Reliability measures were based on the same sample of 50 patients and assessed by the intraclass correlation coefficient (ICC) and related $95 \%$ confidence interval $(95 \% \mathrm{CI})$.

\section{Phase 2: the observational study}

In the second phase, the assessment of metric properties of the BI-d scale was carried out on an additional sample of 169 patients and internal consistency, validity, and responsiveness of BI-d were evaluated.

\section{Study subjects}

In the period between June 2013 and September 2014, 169 consecutive patients (Phase 2) were enrolled. The inclusion criteria were as follows: patients with any CRD (mainly COPD, emphysema, and chest wall diseases) admitted to any of three rehabilitation wards and with arterial blood gases (ABG) stability. In-hospital rehabilitation program was proposed after hospitalization or by general practitioner/pulmonologist due to progressive worsening of disability. Patients were excluded if any of the following were present: presence of respiratory exacerbation with clinical instability (fever, persistent purulent sputum, cough, oxygen saturation $<89 \%$ under oxygen supply, respiratory rate at rest $>25$ acts/min, or heart rate $>110$ beats/ min), oncological or degenerative disease, neuromuscular degenerative diseases, and altered cognitive status.

\section{Data collection and assessment}

The patients enrolled in Phase 2, within 48 hours from admission, underwent the following assessments: anthropometrics evaluation (ie, age, sex, body mass index); 
Cumulative Illness Rating Scale (CIRS1 and CIRS2); ${ }^{20}$ forced expiratory volume in 1 second $\left(\mathrm{FEV}_{1}\right) \%$ predicted; forced vital capacity (FVC\% predicted); residual volume; ABG analysis ( $\mathrm{pH}$, arterial partial pressure of oxygen $\left(\mathrm{PaO}_{2}\right)$, arterial partial pressure of carbon dioxide $\left(\mathrm{PaCO}_{2}\right)$, inspiratory fraction of oxygen $\left(\mathrm{FiO}_{2}\right), \mathrm{PaO}_{2} / \mathrm{FiO}_{2}$ to normalize the $\mathrm{ABG}$ with different $\mathrm{FiO}_{2}$ ); ongoing pharmacological therapy; exercise tolerance measured by the 6-minute walk test; the Medical Research Council (MRC) dyspnea scale, ${ }^{21} \mathrm{BI}$ to assess motor disability using the Shah's weight version; ${ }^{19}$ and the BI-d scale asking how the perceived subjective dyspnea was item by item.

Before discharge (within the last 24 hours of hospital stay), the patients underwent the following assessments again: ABG analysis, 6-minute walk test, MRC dyspnea scale, BI, and BI-d. The scales were always administered face to face by an expert interviewer (physiotherapist). For each patient, the number of pulmonary rehabilitation sessions was recorded.

\section{Statistical methods}

Descriptive statistics were performed reporting means and standard deviations [mean (SD)] for quantitative variables, frequencies, and percentages for qualitative variables. In the case of clearly non-Gaussian distributions of quantitative variables, medians, and interquartile ranges (IR) (expressed as difference between the 75 th and 25 th quartile) were reported. Internal consistency was measured through Cronbach's alpha. Both concurrent and divergent validity were assessed using Pearson correlation coefficient for analyses on quantitative variables and Spearman correlation in the case of ordinal variables. Responsiveness was investigated studying differences between pre- and postpulmonary rehabilitation. For this purpose a Kruskal-Wallis test was applied. In order to test the ability of the scale to detect subgroups of patients, the population was divided into two specific dyspnea subgroups of patients, with chronic respiratory failure (CRF) and without $\mathrm{CRF}$. CRF was defined as a patient presenting $\mathrm{PaO}_{2} / \mathrm{FiO}_{2}<290\left(\mathrm{PaO}_{2} / \mathrm{FiO}_{2}\right.$ has been chosen to normalize the available $\mathrm{ABG}$ values under different $\mathrm{FiO}_{2}$, prescribed by doctors) and differences between the two subgroups were investigated by means of a Mann-Whitney $U$-test. The data were analyzed by using Statistical Package for Social Science (SPSS, version 19; IBM Corporation, Armonk, NY, USA) software.

\section{Results}

\section{Phase I: stage I}

A focus group was conducted in a group of ten patients (five COPD, five with restrictive disease - one with interstitial lung disease and four with chest wall disease - mean age, 65.8 (6.2) years; four were female). With the aim to achieve consensus for each item included in BI-d, patients were asked to describe it as "clear" or "unclear". All patients evaluated the scale as easily understandable. Final version of BI-d is reported in the Table $\mathrm{S} 1$.

\section{Phase I: stage 2}

A pilot test on 50 patients (16 female, 34 male), mean age, 66.1 (8.4) years; $\mathrm{FEV}_{1} \%$ predicted, 60\% (19); FVC\% predicted, 80\% (27); $\mathrm{FEV}_{1} / \mathrm{FVC}$, 52\% (26) was conducted. Patients who fulfilled the inclusion criteria were selected for the preliminary study to assess the amount of time taken and questionnaire comprehensibility for the patients. The average time to administer the questionnaire was 163 (50) seconds.

\section{Patient-perceived comprehensibility}

The median rank was 3 (no difficulties) with a range 0-3 showing that patients considered the scale easy or very easy.

\section{Reliability}

Both interrater and test-retest reliability reached high levels, considering that the interrater ICC was 0.93 (95\% CI 0.892-0.964) and test-retest ICC was 0.99 (95\% CI 0.983-0.994).

\section{Phase 2}

\section{Patient characteristics}

The demographic and clinical characteristics of the whole study group $(n=169)$ are presented in Table 1.

\section{Metric properties of the Bl-d Internal consistency}

The internal consistency measured with Cronbach's alpha was 0.89 .

\section{Concurrent validity}

Relationships between BI-d and both 6 minute walking distance, as measure of effort tolerance, and MRC dyspnea scale, as measure of dyspnea, were assessed. Strong correlation between meters at 6-minute walking distance and the BI-d scale (Pearson $r=-0.538, P<0.001$ ) (Figure 1) as well as between MRC and BI-d (Spearman $r_{\mathrm{s}}=0.70, P<0.001$ ) were observed. Figure 2 shows a box plot of the relationship between BI-d and MRC grading score. Increasing levels of BI-d were observed across increasing values of MRC from 0 to 4 . A significant difference $(P<0.01)$ was detected in post hoc analyses between BI-d at score 4 of MRC and each of the other subgroups. 
Table I Baseline characteristics of the 169 studied patients

\begin{tabular}{|c|c|}
\hline Variable & Mean (SD) \\
\hline BMI & $27.91(6.76)$ \\
\hline CIRSI & $1.66(0.46)$ \\
\hline CIRS2 & $2.93(1.7 I)$ \\
\hline $\mathrm{FEV}_{1}, \%$ predicted & $58(27)$ \\
\hline FVC, \% predicted & $82(23)$ \\
\hline FEV,/FVC, \% & $72(25)$ \\
\hline \multicolumn{2}{|c|}{ GOLD stages in patients with COPD, $\mathrm{n}(\%)$} \\
\hline \multicolumn{2}{|l|}{ GOLD I: I I (8.I) } \\
\hline \multicolumn{2}{|l|}{ GOLD II: 31 (22.8) } \\
\hline \multicolumn{2}{|l|}{ GOLD III: 31 (22.8) } \\
\hline \multicolumn{2}{|l|}{ GOLD IV: 63 (46.32) } \\
\hline $\mathrm{pH}$ & $7.43(0.05)$ \\
\hline $\mathrm{PaCO}_{2}, \mathrm{mmHg}$ & $45(27)$ \\
\hline $\mathrm{PaO}_{2} / \mathrm{FiO}_{2}$ & $314(6 I)$ \\
\hline 6MWD, m & $279(143)$ \\
\hline Barthel Index (score) & $94(14)$ \\
\hline CRF, n (\%) & $69(4 I)$ \\
\hline Diagnosis & n (\%) \\
\hline$\overline{\text { COPD }}$ & $136(80)$ \\
\hline Restrictive lung disease* & $20(12)$ \\
\hline ILD & $4(2)$ \\
\hline Other & $9(6)$ \\
\hline Pharmacotherapy & n (\%) \\
\hline None & $33(19)$ \\
\hline LAMA & $15(9)$ \\
\hline LABA + LAMA & $45(27)$ \\
\hline LABA + LAMA + ICS & $76(45)$ \\
\hline LTOT & $69(4 I)$ \\
\hline
\end{tabular}

Note: *2 ILD and I8 chest wall disease.

Abbreviations: BMI, body mass index; CIRS, Cumulative Illness Rating Scale; COPD, chronic obstructive pulmonary disease; CRF, chronic respiratory failure; $\mathrm{FEV}_{1}$, forced expiratory volume in I second; $\mathrm{FiO}_{2}$, inspiratory fraction of oxygen; FVC, forced vital capacity; GOLD, Global Initiative for Chronic Obstructive Lung Diseases; ICS, inhaled corticosteroid; ILD, interstitial lung diseases; LABA, longacting beta2-agonist; LAMA, long-acting muscarinic antagonist; LTOT, long-term oxygen therapy; 6MWD, 6-minute walk distance; $\mathrm{PaCO}_{2}$, arterial partial pressure of carbon dioxide; $\mathrm{PaO}_{2}$, arterial partial pressure of oxygen; $\mathrm{SD}$, standard deviation.

\section{Divergent validity}

Relationship between motor disability and dyspnea showed a low correlation (Pearson $r=-0.38$ ) between BI-d and BI.

\section{Responsiveness}

The BI-d demonstrated a significant change over time in the level of perceived dyspnea across the whole population, from a median of 21 (IR: 28.5) to a median of 9.5 (IR: 15.25), $P<0.001$.

Patients underwent 20 (4) days of individually tailored rehabilitation activities, including lower and upper limbs endurance training, respiratory muscle training, and peripheral muscle strength exercises. After rehabilitation, a significant improvement $(P<0.001)$ was also seen for all BI-d items.

Conversely, BI total score remained unchanged between admission and discharge (median value 98 and IR: 5).

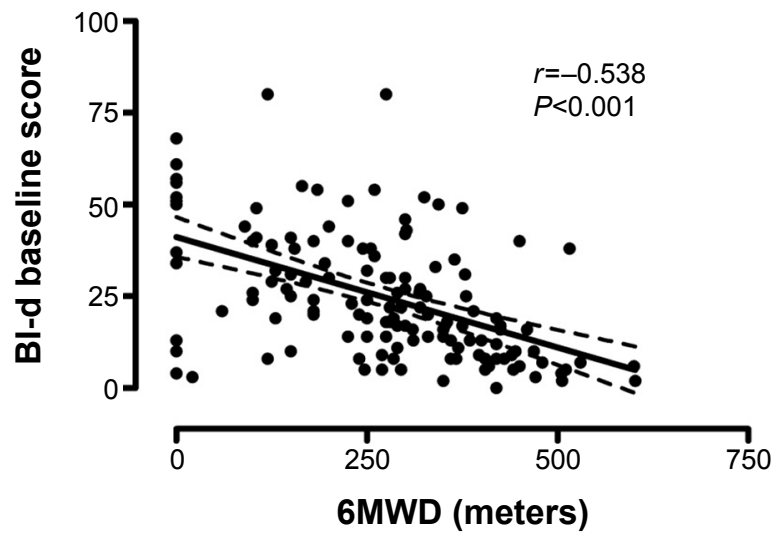

Figure I Correlation between meters at 6MWD and the BI-d scale. Abbreviations: BI-d, Barthel Index-dyspnea; 6MWD, 6-minute walking distance.

Figure 3 describes the mean score of each BI-d item at admission (dark line) and discharge (gray line). The activities in which the highest level of dyspnea was observed were climbing stairs, walking, and taking a shower/bath. The activities with the lowest degree of dyspnea observed were bladder control, bowel control, and eating.

The BI-d showed good properties in differentiating between patients with and without chronic respiratory failure (CRF). Table 2 shows median assessed at the beginning (T0) and at the end (T1) of the rehabilitative program using the two indexes BI and BI-d in the two subgroups (no CRF vs yes $\mathrm{CRF}$ ).

\section{Discussion}

The presence of the dyspnea symptom can influence the execution of basic daily activities in patients affected by CRDs.

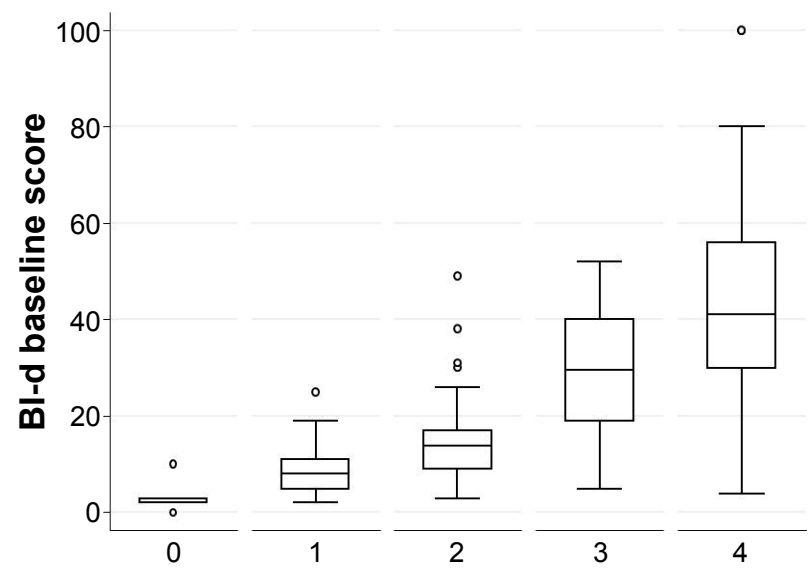

Figure 2 Box plot of distribution of BI-d according to MRC dyspnea score grading (0-4) measured at baseline.

Notes: Statistical significance $(P<0.00 \mathrm{I})$ was found among MRC dyspnea score grading groups; statistical significance $(P<0.01)$ was found between MRC grade 4 and all the other MRC grading groups.

Abbreviations: BI-d, Barthel Index-dyspnea scale; MRC, Medical Research Council. 


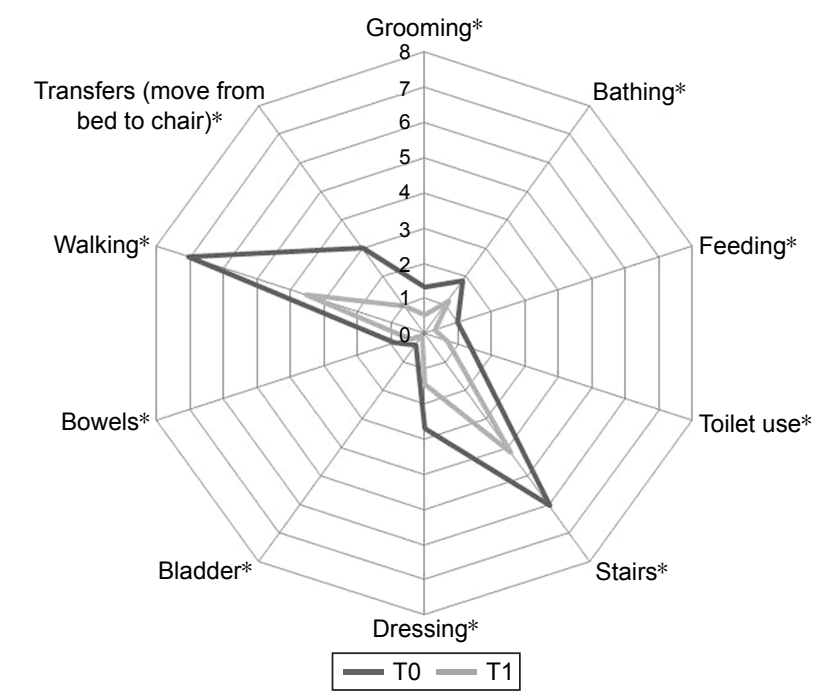

Figure 3 Mean distribution of each BI-d item at admission (dark line) and discharge (gray line).

Note: $* P<0.00$ I over time.

Abbreviation: BI-d, Barthel Index-dyspnea.

Patients with COPD were found to have breathlessness during normal physical activities, such as washing, drying, and dressing. ${ }^{18,22-24}$

In clinical practice, the motor autonomy and ability of chronic patients are often evaluated through the well-known modified BI. ${ }^{19}$ However, the burden of motor disability on ADLs in patients with chronic pulmonary diseases is different from that seen in patients with neuromotor difficulties, because it is heavily influenced by the presence of the dyspnea symptom. The symptom's presence can influence the execution of basic daily activities, making them discontinuous, or extremely slow.

To the best of our knowledge, no study is available on the adaption of a standardized ADL scale, such as BI, to assess the impact of breathlessness on performance of each ADL with the possibility to measure, simultaneously and with a unique instrument, both motor and respiratory disability.

Table 2 Median assessed at the beginning (TO) and at the end ( $\mathrm{TI}$ ) of the rehabilitative program using the two indexes $\mathrm{BI}$ and $\mathrm{BI}$ assessing dyspnea perception (BI-d) in the two subgroups (no CRF vs yes CRF)

\begin{tabular}{lllllll}
\hline & \multicolumn{2}{l}{ No CRF } & Delta (\%) & \multicolumn{2}{c}{ Yes CRF } & \multirow{2}{*}{ Delta (\%) } \\
\cline { 2 - 3 } & T0 & TI & & T0 & TI & \\
\hline BI score & 98 & 100 & +2 & 97 & 98 & +2 \\
BI-dyspnea score & 14 & 7 & -50 & 27 & 15 & -50 \\
MRC score & 2 & 2 & 0 & 3 & 2 & -33 \\
6MWD, meters & 315 & 390 & +24 & 225 & 300 & +33
\end{tabular}

Abbreviations: BI, Barthel Index; Bl-d, Barthel Index dyspnea; CRF, chronic respiratory failure; MRC, Medical Research Council; 6MWD, 6 minute walk distance.
The MRC scale ${ }^{21}$ assesses dyspnea by asking which activities, ranging from vigorous exercise to minimal ADLs, are limited by dyspnea. The MRC evaluates the impact of dyspnea on many of the activities in the BI, albeit with a greater emphasis on mobility. However, scales such as the MRC are indirect; they do not actually ask the patient how much dyspnea they experience assessing the degree to which breathlessness limits mobility.

Following a previous experience, ${ }^{25}$ we considered it useful to maintain the same items as in the modified BI's score because keeping the same items for the subjective analysis of dyspnea made the BI-d's comprehension easier and permitted collection of important information useful for a respiratory rehabilitation program. The scale's acceptability reported by the patients was good, as well as the time spent to administer the scale. Therefore, the results show that the BI-d scale is a reliable and efficient instrument for investigating the level of dyspnea during daily activities in patients affected by CRD.

In order to test the effectiveness of the new score, we hypothesized a good agreement between BI-d total score and MRC measure (considered the gold standard). In fact, we found a good relation between the two scales, even if there was not a complete correspondence with the symptoms studied by the MRC. However, this fact was predictable, as the BI-d scale examines eleven daily activities, while the MRC scale considers just the walking activity. A major drawback of the MRC scale is the lack of a scale point for patients who experience dyspnea during different ADLs. The MRC scale is a strong tool for patient severity stratification according to breathless level; however, due to the restricted amplitude of score that may produce floor and ceiling effects, it is somehow difficult to point out minimal but clinically significant patient improvements after treatments (drugs and rehabilitation). On the contrary, we believe that a multi-items score focusing on different basic ADLs and dsypnea may better describe the real disability and modifications following rehabilitation programs.

The internal consistency, namely the degree to which the survey's items are connected, and their ability to measure the same concept, was demonstrated by the good Cronbach alpha value showing the intrinsic homogeneity of the new instrument. In addition, the BI-d scale shows a good reliability, both interoperator and at the test-retest assessment. This demonstrates the generalizability of the instrument to different clinical and rehabilitative settings. The BI-d scale is able to capture changes following the rehabilitation program, showing that it could become a new outcome marker 
of CRF. The BI-d shows a good internal consistency, as well as a good validity. Furthermore, the scale demonstrated a good ability to separate significantly, patients with CRF from those without CRF.

The good correlation between the BI, effort tolerance, and the BI-d scale shows that the general motor autonomy reduction in daily life is only partially able to describe the dyspnea disability during the same daily activities.

As study limitations, we did not create a new customized score based on ADL conditions found as the worst for dyspnea, but we decided to use "a priori" for all the items present in the BI score. The study includes mainly patients with COPD (80\%) and thus the results are not well generalized into all respiratory patient populations; this fact reduces the applicability of the results for all respiratory conditions. The sample of patients with respiratory disease involved in this study was in a stable state, while patients with acute problems could present completely different results.

American Thoracic Society statement on dyspnea ${ }^{26}$ recommends categorizing measures as pertaining to domains of sensory-perceptual experience (what breathing feels like), affective distress, or symptom impact or burden. A BI-d measure such as presented in this study attempts to quantify the extent to which functional abilities are limited by dyspnea; therefore, it should be classified as a measure of dyspnea impact or burden.

We believe that this BI adaptation may be considered a complementary tool to the existing instruments for assessing some aspect of dyspnea in the respiratory population; the combined administration of the BI and the BI-d scale, with a unique and simple instrument administered simultaneously, could be useful in defining multifactor disability (both motor and dyspnea impact-related) and the corresponding components to include in different rehabilitation programs.

Future studies, 1) should include oxygen output measurement in order to assess which ADL is more involved and if it is associated to increased dyspnea, 2) should define the BI-d's applicability in a large population, in different diseases prone to dyspnea during ADLs, with or without comorbidities, and in different clinical settings.

\section{Conclusion}

The BI-d is proved to be reliable, sensitive, and adequate as a tool for measuring the level of dyspnea perceived in performing basic daily living activities. Moreover, it is easy and quick to administer and it is correlated to the MRC scale. Based on this fact, this BI modification for dyspnea would aspire to add important information to patient's level of motor disability, in patients who have CRD. Further studies using BI-d in respiratory rehabilitation programs are mandatory.

\section{Acknowledgments}

The authors thank Laura Comini (Scientific Direction S. Maugeri Foundation, IRCCS, Institute of Lumezzane, Brescia) for her constructive criticism in preparing the paper, Rosemary Allpress for the English revision of the manuscript, Carla Simonelli and Maria Laura Bertussi (Respiratory Rehabilitation Division, S. Maugeri Foundation, IRCCS, Institute of Lumezzane, Brescia) and Vito Spinelli (Respiratory Division, S. Maugeri Foundation, IRCCS, Institute of Cassano delle Murge, Bari) for their important clinical contribution.

\section{Author contributions}

All authors made substantial contributions to conception and design, acquisition of data, or analysis and interpretation of data; took part in drafting the article or revising it critically for important intellectual content; gave final approval of the version to be published; and agree to be accountable for all aspects of the work.

\section{Disclosure}

The authors report no conflicts of interest in this work.

\section{References}

1. Elliott MW, Adams L, Cockcroft A, Macrae KD, Murphy K, Guz A. The language of breathlessness: use of verbal descriptors by patients with cardiorespiratory disease. Am Rev Respir Dis. 1991;144(4):826-832.

2. Spruit MA, Singh SJ, Garvey C, et al; On behalf of the ATS/ERS Task Force on Pulmonary Rehabilitation. An Official American Thoracic Society/European Respiratory Society statement: key concepts and advances in pulmonary rehabilitation. Am J Respir Crit Care Med. 2013; 188(8):e13-e64.

3. Crisafulli E, Clini EM. Measure of dyspnea in pulmonary rehabilitation. Multidiscip Respir Med. 2010;5(3):202-210.

4. Mahler DA, Weinberg DH, Wells CK, Feinstein AR. The measurement of dyspnea. Contents, interobserver agreement, and physiologic correlates of two new clinical indexes. Chest. 1984;85(6):751-758.

5. Abma IL, van der Wees PJ, Veer V, Westert GP, Rovers M. Measurement properties of patient-reported outcome measures (PROMs) in adults with obstructive sleep apnea (OSA): A systematic review. Sleep Med Rev. 2015;28:14-27.

6. Jones PW, Quirk FH, Baveystock CM, Littleiohns P. A self complete measure for chronic airflow limitation - the Saint George's Respiratory Questionnaire. Am Rev Respir Dis. 1992;145(6):1321-1327.

7. Jones PW, Harding G, Berry P, Wiklund I, Chew W-H, Kline Leidy N. Development and first validation of the COPD Assessment Test. Eur Respir J. 2009;34(3):648-654. 
8. Vidotto G, Bertolotti G, Carone M, et al. A new questionnaire specifically designed for patients affected by chronic obstructive pulmonary disease, The Italian Health Status Questionnaire. Respir Med. 2006; 100(5):862-870.

9. Lareau SC, Meek PM, Roos PJ. Development and testing of the modified version of the pulmonary functional status and dyspnea questionnaire (PFSDQ-M). Heart Lung. 1998;27(3):159-168.

10. Partridge MR, Miravitlles M, Ståhl E, Karlsson N, Svensson K, Weltee T. Development and validation of the Capacity of Daily Living during the Morning questionnaire and the Global Chest Symptoms Questionnaire in COPD. Eur Respir J. 2010;36(1):96-104.

11. Garrod R, Bestall JC, Paul EA, Wedzicha JA, Jones PW. Development and validation of a standardized measure of activity of daily living in patients with severe COPD: the London Chest Activity of Daily Living scale (LCADL). Respir Med. 2000;94(6):589-596.

12. Yorke J, Moosavi SH, Shuldham C, Jones PW. Quantification of dyspnoea using descriptors: development and initial testing of the Dyspnoea-12. Thorax. 2010;65(1):21-26.

13. Wilcox TK, Chen WH, Howard KA, et al. Item selection, reliability and validity of the Shortness of Breath with Daily Activities (SOBDA) questionnaire: a new outcome measure for evaluating dyspnea in chronic obstructive pulmonary disease. Health Qual Life Outcomes. 2013; 11:196.

14. Jolley CJ, Moxham J. A physiological model of patient-reported breathlessness during daily activities in COPD. Eur Respir Rev. 2009;18(112): 66-79.

15. Howard K, Berry P, Petrillo J, et al. Development of the shortness of breath with daily activities questionnaire (SOBDA). Value Health. 2012; 15(8):1042-1050.

16. Yoza Y, Ariyoshi K, Honda S, Taniguchi H, Senjyu H. Development of an activity of daily living scale for patients with COPD: The Activity of Daily Living Dyspnoea scale. Respirology. 2009;14(3): 429-435.
17. Maekura R, Hiraga T, Miki K, et al. Personalized pulmonary rehabilitation and occupational therapy based on cardiopulmonary exercise testing for patients with advanced chronic obstructive pulmonary disease. Int J Chron Obstruct Pulmon Dis. 2015;10:1787-1800.

18. Braido F, Baiardini I, Menoni S, et al. Disability in COPD and its relationship to clinical and patient-reported outcomes. Curr Med Res Opin. 2011;27(5):981-986.

19. Shah S, Vanclay F, Cooper B. Improving the sensitivity of the Barthel Index for stroke rehabilitation. J Clin Epidemiol. 1989;42(8): 703-709.

20. Linn BS, Linn MW, Guerel L. Cumulative Illness Rating scale. J Am Geriatr Soc. 1968;16(5):622-626.

21. Fletcher CM. Standardised questionnaire on respiratory symptoms: a statement prepared and approved by the MRC Committee on the Aetiology of Chronic Bronchitis (MRC breathlessness score). BMJ. 1960;2: 1965-1968.

22. Brooks JM, Donohue J, Anzueto A, et al. Shortness of Breath with Daily Activities questionnaire: validation and responder thresholds in patients with chronic obstructive pulmonary disease. BMJ Open. 2013;3(10): e003048.

23. Rennard S, Decramer M, Calverley PM, et al. Impact of COPD in North America and Europe in 2000: subjects' perspective of Confronting COPD International Survey. Eur Respir J. 2002;20(4):799-805.

24. Partridge MR, Karlsson N, Small IR. Patient insight into the impact of chronic obstructive pulmonary disease in the morning: an internet survey. Curr Med Res Opin. 2009;25(8):2043-2048.

25. Lee YC, Chen SS, Koh CL, Hsueh IP, Yao KP, Hsieh CL. Development of two Barthel Index-based Supplementary Scales for patients with stroke. PLoS One. 2014;9(10):e110494.

26. Parshall MB, Schwartzstein RM, Adams L, et al. An Official American Thoracic Society statement: update on the mechanisms, assessment, and management of dyspnea. Am J Respir Crit Care Med. 2012;185(4) $435-452$. 


\section{Supplementary materials Guidelines for administration of the Barthel Dyspnea Scale}

The following phrases simulate the interview between operator and patient:

Dear Mr/Ms XXX, now, I will submit a questionnaire investigating your current level of dyspnea (within the last 2 days) during the same activities of daily life (ADLs) that I just described, for your limitations of the musculoskeletal system.

You will give a judgment to your dyspnea as follows: $0=$ no sign of dyspnea during execution of ADLs; $1=$ slight dyspnea that doesn't prevent or slow down execution of ADLs; $2=$ moderate dyspnea, which can slow down ADLs; $3=$ severe dyspnea, which can greatly slow down ADLs; $4=$ extremely severe level of dyspnea, such as to preclude or reduce that activity. Now we begin the questionnaire analyzing the individual activities of daily life for which you will give me your score of your dyspnea.

The patient was holding a summary of the five options of severity of dyspnea, but he had no feedback about the content of the questions posed by the operator.

The operator read the following questions to the patient and then filled out the proper score from their responses:
1. "What is the degree of dyspnea during the course of your grooming-personal hygiene (washing your face, hair, teeth, shaving)?"

2. "What is the degree of dyspnea when bathing?"

3. "What is the degree of dyspnea when feedingeating?"

4. "How is the degree of dyspnea when using the toilet (get up and sit by the water, undress and get dressed to go to the toilet)?"

5. "What is the degree of dyspnea when going up or down a flight of stairs?"

6. "What is the degree of dyspnea when dressing, including socks and shoes?"

7. "What is the degree of dyspnea when you must urinate?"

8. "What is the degree of dyspnea when you must defecate?"

9. "What is the degree of dyspnea when you walk at your own pace (more than $50 \mathrm{~m}$ )?"

9b. "What is the degree of dyspnea in case you need to use the wheelchair to get around for more than $50 \mathrm{~m}$ ?"

10. "What is the degree of dyspnea when you are performing transfers, such as from bed to chair or vice versa?"

Table SI BI-d

\begin{tabular}{|c|c|c|c|c|c|}
\hline \multirow{2}{*}{$\begin{array}{l}\text { Items } \\
\text { Options }\end{array}$} & \multicolumn{5}{|c|}{ Assessment } \\
\hline & 0 & I & 2 & 3 & 4 \\
\hline Grooming & 0 & I & 3 & 4 & 5 \\
\hline Bathing & 0 & I & 3 & 4 & 5 \\
\hline Feeding & 0 & 2 & 5 & 8 & 10 \\
\hline Toilet use & 0 & 2 & 5 & 8 & 10 \\
\hline Stairs & 0 & 2 & 5 & 8 & 10 \\
\hline Dressing & 0 & 2 & 5 & 8 & 10 \\
\hline Bowels & 0 & 2 & 5 & 8 & 10 \\
\hline Bladder & 0 & 2 & 5 & 8 & 10 \\
\hline Mobility & 0 & 3 & 8 & 12 & 15 \\
\hline Wheelchair* & 0 & I & 3 & 4 & 5 \\
\hline Transfers (bed to chair and back)* & 0 & 3 & 8 & 12 & 15 \\
\hline
\end{tabular}

Notes: *Not to be filled in if the patient is able to walk. Answer options: $0=$ no sign of dyspnea during execution of ADLs; I= slight dyspnea that does not prevent or slow down execution of ADLs; $2=$ moderate dyspnea, which can slow down ADLs; $3=$ severe dyspnea, which can greatly slow down ADLs; $4=$ extremely severe level of dyspnea, such as to preclude or reduce that activity.

Abbreviations: ADLs, activities of daily living; BI-d, Barthel Index-dyspnea.

International Journal of COPD

\section{Publish your work in this journal}

The International Journal of COPD is an international, peer-reviewed journal of therapeutics and pharmacology focusing on concise rapid reporting of clinical studies and reviews in COPD. Special focus is given to the pathophysiological processes underlying the disease, intervention programs, patient focused education, and self management protocols.

\section{Dovepress}

This journal is indexed on PubMed Central, MedLine and CAS. The manuscript management system is completely online and includes a very quick and fair peer-review system, which is all easy to use. Visit $\mathrm{http} / / / \mathrm{www}$.dovepress.com/testimonials.php to read real quotes from published authors. 